\title{
Time outdoors and the prevention of myopia
}

\author{
Q6 Amanda N. French ${ }^{a}$, Regan S. Ashby ${ }^{b}$, Ian G. Morgan ${ }^{c, *}$, Kathryn A. Rose ${ }^{\text {a }}$ \\ ${ }^{a}$ Discipline of Orthoptics, Faculty of Health Sciences, University of Sydney, Lidcombe, NSW 2011, Australia \\ ${ }^{\mathrm{b}}$ Faculty of Applied Sciences, University of Canberra, Bruce, ACT 2609, Australia \\ ${ }^{\mathrm{c}}$ Research School of Biology, Australian National University, GPO Box 475, Acton, ACT 2601, Australia
}

\section{A R T I C L E I N F O}

\section{Article history:}

Received 1 March 2013

Accepted in revised form 23 April 2013

Available online $\mathrm{xxx}$

\section{Keywords:}

myopia

incident myopia

myopia progression

prevention

outdoors

light

dopamine

spiperone

clinical trial

\begin{abstract}
A B S T R A C T
Recent epidemiological evidence suggests that children who spend more time outdoors are less likely to be, or to become myopic, irrespective of how much near work they do, or whether their parents are myopic. It is currently uncertain if time outdoors also blocks progression of myopia. It has been suggested that the mechanism of the protective effect of time outdoors involves light-stimulated release of dopamine from the retina, since increased dopamine release appears to inhibit increased axial elongation, which is the structural basis of myopia. This hypothesis has been supported by animal experiments which have replicated the protective effects of bright light against the development of myopia under laboratory conditions, and have shown that the effect is, at least in part, mediated by dopamine, since the D2-dopamine antagonist spiperone reduces the protective effect. There are some inconsistencies in the evidence, most notably the limited inhibition by bright light under laboratory conditions of lens-induced myopia in monkeys, but other proposed mechanisms possibly associated with time outdoors such as relaxed accommodation, more uniform dioptric space, increased pupil constriction, exposure to UV light, changes in the spectral composition of visible light, or increased physical activity have little epidemiological or experimental support. Irrespective of the mechanisms involved, clinical trials are now underway to reduce the development of myopia in children by increasing the amount of time they spend outdoors. These trials would benefit from more precise definition of thresholds for protection in terms of intensity and duration of light exposures. These can be investigated in animal experiments in appropriate models, and can also be determined in epidemiological studies, although more precise measurement of exposures than those currently provided by questionnaires is desirable.
\end{abstract}

(c) 2013 Elsevier Ltd. All rights reserved.

\section{1. Introduction}

An epidemic of myopia has emerged in children and young adults in some of the countries of East and Southeast Asia (Morgan et al., 2012), in particular in Singapore (Wu et al., 2001), China (He et al., 2004; Qian et al., 2009), including Hong Kong (Goh and Lam, 1994) and Taiwan (Lin et al., 2004; Shih et al., 2009), Japan (Matsumura and Hirai, 1999) and Korea (Jung et al., 2012). In these locations, around $80 \%$ or more of children completing school are now short-sighted, and the prevalence of sight-threatening high myopia in these children is now approaching $20 \%$ or more (Lin et al., 2004; Jung et al., 2012). In other parts of the world, the prevalence of myopia also seems to be increasing. The rate of increase is somewhat less than in some parts East and Southeast Asia, but nevertheless, in the United States (Kempen et al., 2004; Vitale et al.,

\footnotetext{
* Corresponding author. Tel.: +61 417450746; fax: +61 261253808.

E-mail address: ian.morgan@anu.edu.au (I.G. Morgan).
}

2008, 2009), and perhaps in Europe (Logan et al., 2005; Jobke et al., 2008), the prevalence of myopia in younger adults is now in the range of $30-50 \%$.

These high prevalences of myopia pose a major public health challenge. The high prevalence of ordinary myopia, which can be largely corrected with glasses, contact lenses or refractive surgery, poses the challenge of providing appropriate correction to the large number of people who now require it, because World Health Organisation (WHO) analyses show that uncorrected refractive error is the major cause of visual impairment in the world (Resnikoff et al., 2008). In addition, a meta-analysis of 11 crosssectional studies has shown an increased risk of open angle glaucoma with both low and high myopia, with odds ratios of 1.77 and 1.88 respectively (Marcus et al., 2011). Myopia also poses an increased risk of retinal detachment which increases with the severity of myopia (Chou et al., 2007), and there are associations between myopia and cataract (Leske et al., 1991), although the causal relationship is not clear. Serious complications due to retinal and choroidal pathologies associated with myopia also increase 
with myopia severity (Vongphanit et al., 2002), and pose a major challenge, because prevention of the associated uncorrectable vision loss requires costly ophthalmic treatment (Morgan et al., 2012).

These challenges have focussed attention on the importance of prevention of myopia. Fortunately, recent reviews, from both environmental (Morgan and Rose, 2005) and genetic (Wojciechowski, 2011) perspectives, have concluded that this epidemic is largely due to exposure to environmental risk factors, which may be modifiable, with little evidence of increased susceptibility to the development of myopia based on genetic differences in those ethnic groups which often show higher prevalences of myopia. This conclusion is based on the evidence that within one ethnic group, there are marked differences in the prevalence of myopia in different environments, implicating environmental factors (see for example Rose et al., 2008b). In addition, within one location, specifically Singapore, the prevalence of myopia is high in younger adults from all the major ethnic groups - even in the population of South Asian (Indian) origin which is closer in genetic terms to populations of European and Middle Eastern origin. This evidence has been extensively reviewed elsewhere (Morgan and Rose, 2005; Morgan et al., 2012; Wojciechowski, 2011).

There is, in fact, considerable evidence that myopia is more common in adults who have completed more years of schooling, and who achieved higher qualifications (Au Eong et al., 1993a,b). In children, there is also an almost universal pattern of increasing myopia prevalence with years of schooling, and increased myopia with children with higher examination results (Saw et al., 2007) and those in academically selective schools or streams (Quek et al., 2004). Near work has been intensively investigated as a specific risk factor which could explain these associations, but attempts to quantify near work in recent years have not provided strong support for this idea (Mutti et al., 2002; Ip et al., 2008). Recent work has identified an association at the national level between locations with a high prevalence of myopia and intensive use of extracurricular classes (coaching or cram schools) (Morgan and Rose, 2013), and there is a similar association at the individual level (Saw et al., 2001a,b). It also seems likely that heavy homework and home study loads may have a role. However, given that mass intensive education has been a key component of economic development for many countries, it is not clear that educational loads can be markedly reduced, even though there are a few countries, characterised by more limited use of coaching or cram schools and lower homework loads, where educational outcomes are high, but the prevalence of myopia is low (Morgan and Rose, 2013).

Fortunately, again, recent work has identified an environmental exposure which appears to protect from the development of myopia - children who spend more time outdoors appear to be less likely to be, or become myopic (Mutti et al., 2002; Jones et al., 2007; Rose et al., 2008a,b; Dirani et al., 2009; Jones-Jordan et al., 2011; French et al., 2013a). The aim of this review is to outline the evidence for a protective role for time spent outdoors, to examine the biological mechanisms which underpin it, and to consider the potential of interventions which increase the amount of time that children spend outdoors for prevention of myopia.

\section{Evidence for a protective effect of time outdoors}

\subsection{Major epidemiological studies}

Studies which have addressed the issue of the protection from the development of myopia by time spent outdoors are summarised in Table 1. A direct link between time spent outdoors and myopia was first established in a longitudinal investigation of the factors associated with rate of myopic progression in a cohort of
Finnish school children with established myopia (Parssinen and Lyyra, 1993). Greater time spent outdoors and in sports activities was associated with a less myopic refraction at follow-up and a marginally slower rate of myopic progression, but the association was only statistically significant for boys.

This finding was followed up in the large population-based Orinda Longitudinal Study of Myopia (OLSM) in the United States (Mutti et al., 2002), which reported that children with myopia engaged in significantly less sports activities than children who were emmetropic. The authors proposed that children who spend more time in sport performed less near work and thus did not develop myopia. They also suggested two alternative hypotheses; that children with myopia may participate less in sport due to the impact of spectacle wear or due to a more introverted personality, or that increases in blood flow during exercise might influence eye growth. These findings received little clinical attention, until two abstracts presented at the 2006 ARVO meeting (Jones et al. IOVS 2006; 47: ARVO E-Abstract 5452; Rose et al. IOVS 2006; 47: ARVO EAbstract 5453) stimulated interest in the application of these findings to the prevention of myopia.

Subsequently, Jones et al. (2007) reported that children who became myopic participated in significantly less time outdoors and in sports activities, compared to children who remained emmetropic. They also showed in predictive models that children who spent less time outdoors and on sport had significantly greater odds of becoming myopic. This trend was observed in children with no myopic parents, and in those with two myopic parents. Less protection was observed in children with only one myopic parent, suggesting that there might be an interaction between parental myopia and time outdoors and on sport, which was also found in regression analysis. Nevertheless, protection by increased time outdoors and sport occurred to some extent, irrespective of the number of myopic parents a child had. A subsequent report showed that children who became myopic spent significantly less time outdoors and in sport than children who remained emmetropic, both before and after the onset of myopia (Jones-Jordan et al., 2011). These results strongly suggested that less time spent outdoors was a potentially causal factor for the development of myopia.

Systematic evidence for an effect of time spent outdoors on prevalent myopia was also published in 2008 from the Sydney Myopia Study (SMS), a population-based study of school-aged children in Sydney, Australia (Rose et al., 2008a,b). Time spent outdoors was strongly and inversely related to myopia. Children who spent greater amounts of time outdoors had more hyperopic spherical equivalent refractions and a lower prevalence of myopia than children who spent little time outdoors. This paper separately analysed sport performed outdoors as well as outdoor leisure activities including family picnics, playing outdoors and bushwalking, and indoor sport, and showed that the important factor was the total time spent outdoors, while indoor sport was not protective. Greater time spent outdoors was associated with less myopia even in children performing large amounts of near work. Comparison of the prevalence of myopia in children from the two major ethnic groups in Sydney, those of European and East Asian ancestry, also showed that the lower prevalence of myopia in those of European ancestry was associated with a higher level of time spent outdoors.

To this point, epidemiological studies of time spent outdoors and myopia had been based primarily on samples from populations of largely European origin, with a relatively low prevalence of myopia. However, a similar protective effect of greater time outdoors was reported in a sample of children predominantly of East Asian ancestry in the school-based Singapore Cohort Study of Myopia (SCORM) study (Dirani et al., 2009). Greater time spent 
Table 1

Evidence for a protective effect of increased time outdoors against the development and progression of myopia.

\begin{tabular}{llllll}
\hline Author & Year & $n$ & Participants & Location & Design \\
\hline $\begin{array}{l}\text { Parssinen and } \\
\text { Lyyra }\end{array}$ & 1993 & 238 & $\begin{array}{l}\text { Schoolchildren with } \\
\text { myopia Mean age 11 years } \\
\text { at baseline }\end{array}$ & Finland & $\begin{array}{l}\text { Longitudinal 3 } \\
\text { year follow-up }\end{array}$ \\
& & & &
\end{tabular}
Main findings

\section{Mutti et al. 2002 \\ 336 Population cohort Mean age 14 years \\ United States (OLSM) \\ Saw et al. 2002 \\ 957 Schoolchildren of Chinese ethnicity Age 7-9 years \\ Singapore and Xiamen, China}

Jones et al 2007 age 9 years at baseline

\section{Onal et al. 2007 \\ 207 Medical students Age 18-26 years

\begin{abstract}
Jacobsen et al. 2008 156
\end{abstract} 23.1 years \\ Rose et al. 2008a,b 4088 Population-based age samples; 6 years and 12 years \\ Australia (SMS) \\ Cross-sectional \\ Schoolchildren of Chinese ethnicity Age 6 years Singapore (SCORM) \\ Rose et al. 2008a,b 1249 2009 \\ 1249 Schoolchildren Mean age 14 years \\ Lu et al. 2009 \\ 998 Schoolchildren Mean age 15 years \\ Cross-sectional \\ Turkey

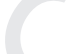 \\ Longitudinal 2 year follow-up}

United States (OLSM)

Cross-sectional

Cross-sectional

Longitudinal 5 year follow-up

Cross-sectional
Children with the slowest myopic progression rate spent more time outdoors per day (3.2 h) than those with the highest progression rate $(1.1 \mathrm{~h}, p=0.003)$. When stratified by gender, boys who spent more time outdoors had slower myopic progression and a more hyperopic final refraction. There was no significant relationship for girls.

Children who were myopic spent significantly less time playing outdoor sport per week $(7.4 \mathrm{~h})$ than children who were emmetropic ( $9.7 \mathrm{~h}, p=0.0003)$. Greater time spent in outdoor sport was associated with significantly lower odds of myopia ( $\mathrm{OR}=0.92, p=0.005)$.

Children in Xiamen had a significantly lower prevalence of myopia compared to children in Singapore (38\% vs. $19 \%$, $p<0.0001)$ and spent greater amounts of time outdoors per week ( 8.7 vs. $3.3 \mathrm{~h}, p<0.0001$ ). Children who were myopic spent less time outdoors than non-myopic children $(p=0.03)$.

Longitudinal 3 Time spent outdoors was not related to incident myopia year follow-up $\quad(\mathrm{RR}=1.01,95 \% \mathrm{CI} 0.98-1.04)$.

Children who were non-myopic spent more time playing sport outside school hours $(4.0 \mathrm{~h})$ than children who were myopic $(1.9 \mathrm{~h}, p<0.0001)$. Children spending greater time playing sport had lower odds of myopia $(\mathrm{OR}=0.89,95 \% \mathrm{CI}$ 0.86-0.93).

Children who became myopic spent significantly less time per week on outdoor and sport activities at baseline $(8 \mathrm{~h})$ compared to children who remained non-myopic $(11.7 \mathrm{~h}$, $p<0.0001$ ). Greater time outdoors significantly reduced the odds of children becoming myopic (OR $=0.91,95 \% \mathrm{CI} 0.87$ -0.94 ). Children with one or two myopic parents who spent greater amounts of time outdoors were also protected from the development of myopia.

Those who had spent most of their time before the age of 7 years in outdoor activities had considerably lower odds of having myopia in young adulthood $(\mathrm{OR}=0.44, p=0.01)$, compared to those who spent most of their time in childhood on indoor activities e.g. video games, television watching.

Students who were myopic spent significantly less time on physical activities (51 min per day) than non-myopic students (60 min per day, $p=0.049$ ) Time spent on physical activity was inversely related to the amount of myopic shift in refraction, with each additional hour of physical activity associated with a reduction in myopic refractive change of 0.175 dioptres.

Children in both age samples who spent more time outdoors had a more hyperopic refraction than children who spent low time outdoors (younger sample ptrend $=0.009$, older sample ptrend $=0.0003$ ). Children in the older sample who spent low time outdoors and high time in near work had the greatest odds of myopia $(\mathrm{OR}=2.6, p=0.02)$. Those who combined high levels of time outdoors with high near work remained protected from myopia.

The prevalence of myopia was significantly higher in the children living Singapore (29\%) in comparison to the children living in Sydney (3\%). Differences in myopia prevalence by location were related to time spent outdoors, with children in Singapore spending significantly less time outdoors than children in Sydney ( $3 \mathrm{~h}$ vs. $14 \mathrm{~h}$ per week). Children with myopia spent significantly less time per day outdoors $(3.1 \mathrm{~h})$ than children without myopia (3.6 h, $p<0.0001$ ). Children who spent more time outdoors had significantly reduced odds of myopia $(\mathrm{OR}=0.90, p=0.004)$. There was no significant difference in the amount of time spent outdoors per week for children with myopia $(6.0 \mathrm{~h})$ compared to those without myopia ( $6.2 \mathrm{~h}, p=0.9$ ). The mean time outdoors for the total study population was very low (6.1 h per week) and the prevalence of myopia was high $83 \%$.

(continued on next page) 
Table 1 (continued)

\begin{tabular}{|c|c|c|c|c|c|c|}
\hline Author & Year & $n$ & Participants & Location & Design & Main findings \\
\hline Low et al. & 2010 & 2639 & $\begin{array}{l}\text { Preschool children Age } \\
6-72 \text { months }\end{array}$ & $\begin{array}{l}\text { Singapore } \\
\text { (STARS) }\end{array}$ & Cross-sectional & $\begin{array}{l}\text { There was no significant difference in time spent outdoors } \\
\text { per day between children with myopia }(0.77 \mathrm{~h} \text { ) and children } \\
\text { without myopia ( } 0.86 \mathrm{~h}, p=0.17) \text {. The odds ratio for myopia } \\
\text { with greater time spent outdoors was not significant for } \\
\text { children of this age (OR }=0.95, p=0.4) \text {. }\end{array}$ \\
\hline Wu et al. & 2010 & 145 & $\begin{array}{l}\text { Schoolchildren Aged 7-12 } \\
\text { years }\end{array}$ & Taiwan & Cross-sectional & $\begin{array}{l}\text { Children who reported often spending time outdoors had } \\
\text { significantly lower odds of myopia }(\mathrm{OR}=0.3,95 \% \mathrm{CI} 0.1 \\
-0.9) \text { than children who seldom spent time outdoors. }\end{array}$ \\
\hline Jones-Jordan et al. & 2011 & 1329 & $\begin{array}{l}\text { Population cohort Aged } \\
6-14 \text { years at baseline }\end{array}$ & $\begin{array}{l}\text { United States } \\
\text { (CLEERE) }\end{array}$ & Longitudinal & $\begin{array}{l}\text { Children who became myopic spent between } 1 \text { and } 2 \mathrm{~h} \text { less } \\
\text { time per week on sports and outdoor activities than an age- } \\
\text { adjusted model of emmetropic children. This difference was } \\
\text { statistically significant from } 4 \text { years prior to myopia onset to } \\
4 \text { years following onset. }\end{array}$ \\
\hline Guggenheim et al. & 2012 & 3061 & $\begin{array}{l}\text { Population birth cohort } \\
\text { Examinations at age } 7,10 \text {, } \\
11,12 \text { and } 15 \text { years }\end{array}$ & $\begin{array}{l}\text { England } \\
\text { (ALSPAC) }\end{array}$ & $\begin{array}{l}\text { Longitudinal } 8 \\
\text { year follow-up }\end{array}$ & $\begin{array}{l}\text { Children at the age of } 8-9 \text { years who participated in high } \\
\text { ( } \geq 3 \mathrm{~h} \text { in summer or } \geq 1 \mathrm{~h} \text { in winter) daily time outdoors } \\
\text { were at significantly less risk of becoming myopic after } 11 \\
\text { years of age (HR }=0.66,95 \% \mathrm{CI} 0.47-0.93 \text { ) compared to } \\
\text { children who participated in low time outdoors. }\end{array}$ \\
\hline Sherwin et al. & 2012a,b & 636 & $\begin{array}{l}61.5 \% \text { of permanent } \\
\text { residents of Norfolk island } \\
\text { aged } 15 \text { years or over }\end{array}$ & $\begin{array}{l}\text { Norfolk Island } \\
\text { (NIES) }\end{array}$ & Cross-sectional & $\begin{array}{l}\text { There was a steady decrease in the prevalence of myopia } \\
\text { with increased proportion of the day spent outdoors, } \\
\text { measured by current activity (ptrend }=0.03 \text { ). However, } \\
\text { there was no significant reduction in odds of myopia with } \\
\text { increased current time outdoors in univariate or } \\
\text { multivariate models. }\end{array}$ \\
\hline Guo et al. & 2013 & 681 & $\begin{array}{l}\text { Schoolchildren, } 2 \text { age } \\
\text { samples; mean } 6.3 \text { years } \\
\text { and } 9.4 \text { years }\end{array}$ & $\begin{array}{l}\text { China (urban } \\
\text { and rural) }\end{array}$ & Cross-sectional & $\begin{array}{l}\text { Children who spent more time outdoors had lower odds of } \\
\text { having myopia (OR }=0.32 ; 95 \% \mathrm{CI}, 0.21-0.48) \text {. Those } \\
\text { children living in the urban region had a higher prevalence } \\
\text { of myopia and spent significantly less time outdoors than } \\
\text { children living in the rural region }(1.1 \mathrm{vs} .2 .2 \mathrm{~h}, p<0.001) \text {. }\end{array}$ \\
\hline French et al. & 2013a,b & 2103 & $\begin{array}{l}\text { Population-based age } \\
\text { cohorts; } 6 \text { and } 12 \text { years at } \\
\text { baseline }\end{array}$ & $\begin{array}{l}\text { Australia (SMS } \\
\text { and SAVES) }\end{array}$ & $\begin{array}{l}\text { Longitudinal } 5-6 \\
\text { year follow-up }\end{array}$ & $\begin{array}{l}\text { Children who became myopic spent less time outdoors } \\
\text { compared to children who remained non-myopic (younger } \\
\text { cohort, } 16.3 \text { vs } 21.0 \mathrm{~h} p<0.0001 \text {, older cohort, } 17.2 \text { versus } \\
19.6 \mathrm{~h}, p=0.001 \text { ). Children who spent low time outdoors in } \\
\text { both cohorts were at increased odds of becoming myopic } \\
\text { (younger cohort, OR }=2.8495 \% \mathrm{CI} 1.56-5.17 \text { and older } \\
\text { cohort, OR }=2.1595 \% \mathrm{CI} 1.35-3.42 \text { ). Those who combined } \\
\text { low time outdoors and high near work were most likely to } \\
\text { become myopic, but those children who performed high } \\
\text { levels of near work and spent high time outdoors remained } \\
\text { protected from myopia development. }\end{array}$ \\
\hline
\end{tabular}

outdoors was associated with significantly less myopic refractions and shorter axial length. Comparison of the three major ethnic groups in Singapore showed that the rank order of myopia prevalence (Chinese $>$ Indians $>$ Malays) was parallelled by an inverse rank order of time spent outdoors (Malays $>$ Indians $>$ Chinese). The protective effect of time outdoors in a population of East Asian origin has since been replicated in school children in greater Beijing from both urban and rural locations, for both refractive error and for axial length (Guo et al., 2013).

Longitudinal follow-up of the two age cohorts ( 6 and 12 years) examined in the SMS also showed that children who became myopic spent significantly less time outdoors at baseline than children who remained non-myopic, and children who were in the highest tertile of time spent outdoors were protected from the development of myopia, irrespective of the amount of near work they performed (French et al., 2013a). Children in the lower tertiles of time spent outdoors had significantly greater odds of becoming myopic, compared to those in the highest tertile. The protective effect of time spent outdoors was strongest in the younger children (aged 6 at baseline), suggesting that the amount of time children spend outdoors when young is particularly important in terms of refractive development.

Time spent outdoors at the age of 8-9 years was also a significant predictor of whether children subsequently became myopic in the Avon Longitudinal Study of Parents and Children (ALSPAC) (Guggenheim et al., 2012). This study also confirmed the greater importance of time outdoors compared to sport.

\subsection{Other supporting studies}

A number of smaller studies have also reported a protective effect of greater time spent outdoors on myopia. In school-aged children located in Amman, Jordan, children who were myopic spent significantly less time playing outdoor sport than children who were non-myopic, and children spending greater time participating in sport has significantly lower odds of being myopic (Khader et al., 2006). A study of medical students in Turkey found an inverse association between time spent outdoors in childhood before age 7 years and myopia (Onal et al., 2007). A significant inverse effect of time outdoors on the odds of having myopia was also reported in a small rural population in Taiwan (Wu et al., 2010).

\subsubsection{How big are the effects?}

A recent meta-analysis pooled the results of 7 cross-sectional studies investigating the association between time spent outdoors and myopia and systematically reviewed the evidence for time outdoors from a further 16 studies that did not meet the inclusion criteria (Sherwin et al., 2012a,b). From the pooled data, which included a majority of studies of school-aged children and one study of preschool-age children, it reported that for each additional hour of time spent outdoors per day there was a $2 \%$ decrease in the odds of myopia. Although these protective effects are small, 2 of the 7 studies included in the meta-analysis found no significant association between myopia and time outdoors. Conversely, the majority of studies that were reviewed, but were 
with children of Chinese ethnicity of the same age living in Singapore. The prevalence of myopia was significantly higher in the children living Singapore (29\%) in comparison to the children living in Sydney (3\%). Multivariate analysis showed that differences in refraction between Sydney and Singapore were strongly related to time spent outdoors, with Chinese children in Singapore spending an average of only $3 \mathrm{~h}$ a week outdoors compared to Chinese children in Sydney with an average of $14 \mathrm{~h}$ per week. There were no significant differences in other parameters, including near work and parental myopia.

A comparison of children of Chinese ancestry growing up in Singapore and Xiamen (Zhan et al., 2000; Saw et al., 2001a,b) also found a significant difference in the prevalence of myopia in the two sites ( 36.7 vs $18.4 \%$ ), and also reported a significant difference in the amount of time spent outdoors between children in the two sites ( $8.7 \mathrm{~h}$ per week in Xiamen versus 3.3 in Singapore).

In a study of children from urban and rural areas of Beijing, the Fig. 1. Odds ratios for prevalent or incident myopia. SMS - Sydney Myopia Study; SAVES - Sydney Adolescent and Vascular Eye Study. Odds ratios are relative to the reference group in each study of high outdoors/low near-work. The decline in odds ratio from the high near-work/low outdoors condition to the high near-work/high outdoors conditions illustrates the protective effect of increasing time outdoors against the highest tertile of near-work. Complete protection would be achieved if the odds ratio had been reduced to one.

not able to be included in the meta-analysis reported more significant positive effects of time outdoors on the protection of myopia.

In contrast to these modest effects, longitudinal data suggest that the chance of becoming myopic is reduced by around one third if time spent outdoors is increased from $0-5 \mathrm{~h}$ per week to 14 or more per week (Jones et al., 2007). In the cross-sectional data from the Sydney Myopia Study (Fig. 1), in 12 year-olds, the odds ratio for myopia for the combination of high near work and low time outdoors was 2.6 compared to the reference group combining low near work and high time outdoors (Rose et al., 2008a). In the subsequent five-year follow-up study (Fig. 1), the same comparison gave odds ratios for incident myopia for 12 year-olds of 15.9 and 5.1 for 17 year-olds (French et al., 2013a). These data all suggest a major Q2 protective effect (Fig. 2).

Three studies have investigated the impact of time outdoors on variation in myopia prevalence in children of the same ethnicity between locations. Rose et al. (Rose et al., 2008a,b) compared a subsample of 6 year old children of Chinese ethnicity from the SMS

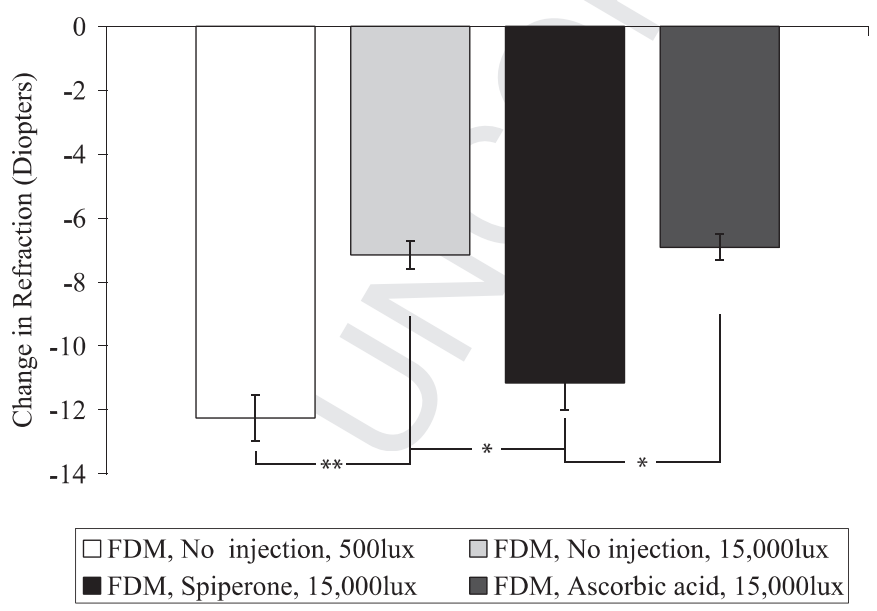

Fig. 2. Evidence for the light-dopamine mechanism of protection against the development of form-deprivation myopia in chickens. In 500 lux light, considerable myopia develops in chickens wearing diffusers. Increasing the light intensity to 15,000 lux reduces the amount of myopia induced. If the D2-dopamine receptor antagonist is injected, then the protective effect is abolished, whereas a control injection has no effect. prevalence of myopia was significantly higher in children living in the urban areas. The prevalence for Grade 1 students in rural areas was $7.9 \%$ for boys and $2.7 \%$ for girls, compared to $29.9 \%$ and $26.6 \%$ respectively in urban areas. The comparable figures for Grade 4 students were rural boys $18.8 \%$, rural girls $15.6 \%$, urban boys $53.2 \%$ and urban girls $76.2 \%$. Children living in the urban location spent significantly less time outdoors than those in rural areas; $1.1 \mathrm{~h}$ per day vs $2.2 \mathrm{~h}$ per day (Guo et al., 2013). A multivariate model showed significant effects for both time outdoors and location.

While time outdoors may not be the only factor involved in these differences, these studies suggest that a significant proportion of the difference between locations in myopia prevalence can be accounted for by differences in time spent outdoors, particularly since in most studies the effects reported for near work are weak. Comparative studies of this kind, while not common in ophthalmic epidemiology, have considerable power because of the often increased variation both in spherical equivalent refraction and in activity parameters.

Thus, while more work is required on exposures and effect sizes, marked differences in the prevalence of myopia can be observed within locations, and between locations, which can, at least in part, be explained by existing differences in time spent outdoors. The magnitude of the effects suggests that significant reductions in the prevalence of myopia could be produced by increasing the amount of time that children spend outdoors during the day, within current behavioural limits.

\subsubsection{Conflicting evidence}

While most papers have reported protective effects of time outdoors against the development of myopia, there are a few studies which have reported no effect. No effect was reported in a school-aged sample in China (Lu et al., 2009), but the sample in this study was predominantly myopic ( $>80 \%$ ), and spent little time outdoors, with a mean of only $6.1 \mathrm{~h}$ per week outside. In contrast, in studies where a protective effect of outdoor activity is evident, children who were not myopic spent over $10 \mathrm{~h}$ of time outdoors. This may point to a possible threshold amount of time spent outdoors per week required to gain adequate protection from the development of myopia. Thus, it is possible that the negative findings were due to a generally below-threshold amount of time spent outdoors, and also perhaps a lack of variation in time spent outdoors.

Another study reported no association between time spent outdoors and myopia in a preschool-aged sample (Low et al., 2010). However, the prevalence of myopia was low in this young age group, as was the level of time outdoors which again may not have been above threshold. However, differential exposures at this age, while not leading to myopia, may contribute to the spherical 
equivalent refraction achieved over the preschool and early school years period - which is important because refractive status during childhood is a major predictor of subsequent progress to myopia. Therefore, it would be useful for future longitudinal studies to determine if the amount of time spent outdoors at preschool-age is associated less hyperopic refraction at that age and with development of myopia in later childhood or adolescence.

Two early studies from Singapore also reported no association between time outdoors and myopia (Saw et al., 2001a,b; Saw et al., 2006). However, significant effects were obtained in more recent studies after adoption of the questionnaire used in the Sydney Myopia Study (Dirani et al., 2009).

In a sample of Danish university students, there was an inverse relationship between physical activity and myopia and change in refraction towards myopia (Jacobsen et al., 2008). This is not necessarily in conflict, and given the current evidence, the effect could actually be due to increased time outdoors, rather than physical activity.

\subsubsection{Does time outdoors control the progression of myopia?}

The ability of increased time outdoors to reduce prevalent and incident myopia appears to depend on limiting axial elongation, since axial length is reduced in parallel with effects on myopia, while other biometric parameters are not affected. Myopic progression in established cases of myopia also depends on axial elongation, and hence it seems plausible that myopic progression would also be reduced by time spent outdoors.

However, in conflict with this hypothesis, a recent detailed study (Jones-Jordan et al., 2012) did not detect an effect of near work or time outdoors on the progression of myopia in those with established myopia. Power calculations were performed to establish that the study had the sufficient power to detect significant effects. A similar finding has been reported by Wu et al. (2013) in a pilot study on myopia prevention.

These finding pose a significant challenge to any hypothesis on the mechanism of the protective effect, since, if regulation of axial elongation is involved, the factors involved would be expected to affect both axial elongation leading to the onset of myopia, and axial elongation leading to progression. However, we do not believe that these findings should be considered definitive.

There is considerable evidence for the existence of seasonal variations in myopic progression - largely derived from the control arms of clinical trials of methods for slowing myopic progression (Table 2). In addition to the references listed in Table 2 (Goss and Rainey, 1998; Fulk et al., 2002; Donovan et al., 2012; Fujiwara et al., 2012; Cui et al., 2013), smaller effects on progression were also reported in Singapore (Tan et al., 2000).

Progression has been consistently shown to be faster in winter and slower in summer, consistent with an effect of increased time outdoors, and since examination periods are generally held before the Northern Hemisphere summer break, also with increased educational load. Thus, if near work and time outdoors do not affect progression, these seasonal effects also need an independent explanation. However, whatever the detailed mechanism, these seasonal studies also help to define the magnitude of effects that might be expected in interventions, and reductions in progression of between 40 and $50 \%$ between the seasons have been reported. This suggests that existing levels of variation in activities could be used to halve the rate of progression, which would make an important contribution to limiting the development of high myopia.

It is possible that the inability to demonstrate statistically significant effects of environmental factors on progression relates to a characteristic of the experimental design, in which studies are carried out only on those with existing myopia. The relationship between time outdoors and the prevalence and development of myopia means that participants with myopia tend to spend less time outdoors, and it is possible that the lack of variation makes it difficult to achieve statistically significant effects. Further studies may benefit from combining investigation of seasonal variation with rigorous documentation of time spent outdoors (and near work parameters).

\subsubsection{Some frequently asked questions}

2.2.4.1. How important are near work and educational load?. In comparison to the clear and consistent effect of time outdoors, effects of near work have been weak and inconsistent, whether near work has been measured as cumulative hours spent on near work activities, or when viewing distance is taken into account, as in the calculation of diopter-hours. The inconsistency and weakness of the near work effects is such that Mutti and Zadnik (2009) have argued that "near work's star has fallen."

However, it should also be noted that methods for estimating near work are highly reliant on recall. Another limitation of estimates of near work is that information has generally been sought on near work activities outside of school, yet it cannot be assumed that the school day is a constant for all children in the same school grade, particularly if factors such as reading distance and reading time without breaks (Ip et al., 2008) are taken into account.

The weakness and inconsistency of the near work effects contrasts markedly with the strong and consistent effects on myopia of years of education, school marks, and educational stream. We have recently argued that more complex measures of educational load, such as amount of homework and home study, and time spent in additional classes out of school may also need to be developed (Morgan and Rose, 2013).

In the context of prevention, the promotion of time outdoors may be more effective than trying to reduce educational load. Given the commitment to educational success that has been a longstanding part of the Confucian tradition, reducing the emphasis on study in East Asia is likely to be a difficult process, even though some countries, such as Australia, demonstrate that it is possible to have internationally competitive educational outcomes without an epidemic of myopia (Morgan and Rose, 2013).

2.2.4.2. Is it sport/physical activity or time outdoors?. Some confusion has been introduced into the area by the early studies which analysed time outdoors and time on sports within one question, and which placed the emphasis on sport rather than time outdoors (Parssinen and Lyyra, 1993; Mutti et al., 2002). This issue was

Table 2

Seasonal differences in myopic progression.

\begin{tabular}{|c|c|c|c|c|}
\hline Reference & Location & Maximum & Minimum & Percent reduction \\
\hline Donovan et al., 2012 & Guangzhou, China & $-0.53 \mathrm{D}$ (winter) & $-0.31 \mathrm{D}($ summer $)$ & $41.5 \%$ \\
\hline Cui et al., 2013 & Copenhagen, Denmark & $-0.32 \mathrm{D}$ (minimum daylight) & $-0.26 \mathrm{D}$ (maximum daylight) & $18.8 \%$ \\
\hline Fulk et al., 2002 & Oklahoma, USA & $-0.32 \mathrm{D}$ (school) & $-0.15 \mathrm{D}$ (summer) & $53.1 \%$ \\
\hline Goss and Rainey, 1998 & Indiana, USA & $-0.72 \mathrm{D}$ (school) & $-0.39 \mathrm{D}$ (summer) & $45.8 \%$ \\
\hline Fujiwara et al., 2012 & Okayama, Japan & 0.17 mm (winter) & $0.14 \mathrm{~mm}$ (summer) & $17.6 \%$ \\
\hline
\end{tabular}


analysed in detail in the Sydney Myopia Study, using the questionnaire available at http://www.cvr.org.au, in which several questions were asked on time outdoors for leisure, time outdoors for sport and time on indoor sport. There was no association between time on indoor sport and myopia, but clear protective associations for both time outdoors on leisure activities and time on outdoor sport, with a particularly strong association for total time outdoors (Rose et al., 2008a). Thus, sport per se does not appear to be important, although clearly one way of encouraging children to spend more time outdoors is through increased participation in outdoor sport.

2.2.4.3. Is there a substitution effect?. Most recent studies have shown that near work is at best only a weak risk factor for the development of myopia (Mutti et al., 2002; Saw et al., 2005; Ip et al., 2008; Rose et al., 2008a). Nevertheless, one possible explanation for the protection afforded by time outdoors is that children who spend a lot of time on study, have less time to spend outdoors, or vice versa. If this was an important part of the explanation, then a significant negative correlation would be expected between hours of near work and hours of time spent outdoors. Four studies (Mutti et al., 2002; Jones et al., 2007; Rose et al., 2008a; Dirani et al., 2009) have considered this issue, and all have found a weak positive correlation between these measures. This suggests that the protection associated with time outdoors is not simply due to a reduction in time spent on near work. However, at strong negative association was reported in the Beijing study (Guo et al., 2013). The conclusion that substitution is not an essential factor is strengthened by the observation in the Sydney Myopia Study that increased time outdoors seems to prevent myopia, irrespective of the amount of near work performed. This has been seen in both cross-sectional analysis of prevalent myopia and in longitudinal analysis of incident myopia (Rose et al., 2008a; French et al., 2013a).

\subsubsection{Are television, computers, mobile phones and hand-held} games important?. An obvious feature of modern life is the increased use of computers, mobile phones and hand-held games, and hence whether they are involved in the emergence of the epidemic of myopia is an important question. In the Sydney Myopia Study analysis, there was no association between time watching television and use of computers with myopia (Rose et al., 2008a). This result was consistent with previous studies on the issue (Mutti et al., 2002; Saw et al., 2006). Some studies count time watching television and time on computers as near work, but, in general the dioptric load associated with television is low, and the dioptric load associated with computer use is about half that associated with reading. Thus it is questionable whether time watching television and time on computers should be counted as near work.

The Sydney Myopia Study did not look at mobile phone use, either for spoken communication, texting, or as a form of handheld game. However, there was a significant negative correlation between use of computer games and myopia. This could possibly be due to a substitution effect of time on computer games for time outdoors, but further analysis of this area is required.

Historical analysis also suggests that these modern technologies were not important factors in the emergence of an epidemic of myopia. The prevalence of myopia was already noticeably increasing in Singapore (Chew et al., 1988; Tay et al., 1992; Au Eong et al., 1993a,b), Taiwan (Lin et al., 2004) and Hong Kong (Goh and Lam, 1994) in the 1960s, well before the proliferation of these devices. Even the later emergence of an epidemic of myopia in China is not consistent with a major role for these devices. However, to the extent that these modern technologies encourage children to stay indoors, they may complicate attempts at prevention.

\section{Summary}

There is strong evidence from both cross-sectional and longitudinal data that children who spend more time outdoors are less likely to be or become myopic. This finding is supported by evidence from studies in a number of different locations and ethnic groups, including those with high prevalences of myopia. Although a small number of studies failed to find a significant association between time outdoors and myopia, it is likely that the population characteristics affected the ability of these studies to detect significant effects. Overall, it is clear that time spent outdoors is important for normal refractive development in children, and that deficits in time spent outdoors are reflected in higher prevalences of myopia. It is currently unclear if time outdoors also slows progression in existing myopes, but the fact that it prevents incident myopia opens up the possibility of preventing the development of myopia, for all but the very low percentage who affected by myopia of clearly genetic aetiology. The effects of time outdoors are large enough to make investigation of its use in prevention worthwhile.

\section{Mechanisms of protection}

A number of potential mechanisms can be suggested for the protective effect of time outdoors. One is simple differences in light intensity. Outdoor environments differ significantly from those indoors in that, at least during the day, the light is brighter - indoor situations are characterised by light intensities in the range of low hundreds up to around one thousand lux, while during the day, outdoors environments are characterised by light intensities of several thousand lux up to 100,000 to 200,000 lux in sunny locations. Outdoor light also includes exposure to UV wave-lengths, and there are other differences in spectral composition of light indoors and outside, as well as diurnal and seasonal changes in spectral composition and intensity.

In addition, viewing distances can be much greater outdoors, and, as argued by Flitcroft (2012), variations in accommodative requirements outdoors are smaller giving a more uniform dioptric space. It also seemed possible that higher light levels outdoors could lead to pupil constriction, increased depth of focus and less image blur, or that reduced accommodation due to more distance viewing could lead to decreased axial elongation. Finally, since children are likely to be somewhat more active outdoors, it also seemed possible that physical activity might be important.

Of these possibilities, Rose et al. (2008a) suggested that increased light intensity outdoors was the most likely, and that this effect could be mediated by light-stimulated release of the retinal transmitter dopamine (Megaw et al., 1997, 2001, 2006), which is known to be able to reduce axial elongation (Iuvone et al., 1991; McCarthy et al., 2007) - the structural basis of the development of myopia. We will refer to this hypothesis as the "light-dopamine" hypothesis.

The evidence for links between retinal dopamine and myopia has been extensively reviewed in this special issue (Feldkaemper and Schaeffel, 2013). The synthesis and release of retinal dopamine is high during the day and low during the night. This rhythm is primarily light-driven (diurnal), although there is also a minor circadian component (Megaw et al., 2006), at least in the chicken, and the rate of release of dopamine appears to increase in a roughly log-linear fashion with increased light intensity (Morgan and Boelen, 1996; Cohen et al., 2012). Dopaminergic function is significantly down-regulated during experimentally-induced periods of increased ocular growth rates (Stone et al., 1989), and more direct indices of dopamine release suggest that dopamine release is reduced within hours of fitting optical devices which result in increased rates of axial elongation (Megaw et al., 2006). In addition, 
dopamine agonists slow the development of experimental myopia (Iuvone et al., 1991; McCarthy et al., 2007). All this evidence suggests that dopamine may play a critical role in the regulation of ocular growth.

The "light-dopamine" hypothesis has been tested in animal studies. In chickens, exposure to high illumination levels $(15,000$ lux $)$ for a period of $5 \mathrm{~h}$ per day, significantly reduced the development of form deprivation myopia (FDM) compared to chicks reared with translucent diffusers under normal laboratory lighting levels (500 lux)(Ashby et al., 2009). High illumination levels were also found to reduce the rate of compensation for negative lenses and enhance the rate of compensation for positive lenses, although full compensation was still achieved (Ashby and Schaeffel, 2010). Similar findings have been reported in tree shrews, where the development of FDM and lens-induced myopia (LIM) was significantly retarded ( $44 \%$ and $39 \%$ respectively) by daily exposure $(7.75 \mathrm{~h}$ ) to 16,000 lux over a period of 11 days (Siegwart et al., IOVS 2012; 53: ARVO E-Abstract 3457). In rhesus monkeys, exposure to high illumination levels significantly retarded the development of FDM (Smith et al., 2012), but had little effect on the rate or end point of compensation for negative lenses (Smith et al., 2013). It is important to note that the conditions of light intensity and duration of exposure which inhibit the development of myopia under experimental conditions are well within the ranges encountered in human environments.

In the chick model, the protective effects of light appear to be greater with higher light intensities (Ashby et al., 2009). Specifically, the development of FDM was reduced if diffusers were removed for a period of 15 min per day under normal laboratory light levels (Napper et al., 1995, 1997). This protective effect is enhanced by exposure to light during the diffuser-free period, proportional to the light intensity used (500 lux, $48 \%$ reduction in FDM; 15,000 lux, $\sim 62 \%$ reduction in FDM; 30,000 lux, $\sim 79 \%$ reduction in FDM)(Ashby et al., 2009). In fact, normal refractive development in chicks reared under light-dark cycles depends significantly on illumination levels (Cohen et al., 2011), since chicks reared under low illumination levels (50 lux) during the light phase of their daily light cycle, for a period of 90 days, developed significant amounts of myopia ( $\sim-2.41 \mathrm{D})$, as compared to those animals reared under medium (500 lux, $\sim+0.03 \mathrm{D}$ ) or high light levels $(10,000$ lux, $\sim+1.1 \mathrm{D})$. This suggests that prolonged exposure to low light intensities may destabilise growth control mechanisms, but these are not conditions to which children who become myopic would generally be exposed.

The involvement of dopamine has been tested in only one experiment. However, it gave results consistent with the hypothesis, since the D2-dopamine antagonist spiperone blocked the protective effect of light against the development of FDM in chickens (Ashby and Schaeffel, 2010).

Overall, there is considerable evidence in favour of the "lightdopamine" hypothesis, but the evidence is not entirely consistent, since, while bright light slows the development of FDM in chickens (Ashby et al., 2009), tree shrews (Moderately elevated fluorescent light levels slow form deprivation and minus lens-induced myopia in tree shrews. Siegwart et al. ARVO E-Abstract \# 3457, 2012) and monkeys (Smith et al., 2012), and slows the development of LIM in chickens (Ashby et al., 2009) and tree shrews (Moderately elevated fluorescent light levels slow form deprivation and minus lensinduced myopia in tree shrews. Siegwart et al. ARVO E-Abstract \# 3457,2012 ), it had only limited effects on the development of LIM in monkeys (Smith et al., 2013), which is generally regarded as a better model of human myopia.

A combination of epidemiological and experimental evidence suggests that the other mechanisms proposed are less plausible. In relation to distance viewing and relaxed accommodation outdoors, this idea does not fit with the evidence from animal studies that accommodation is not a critical factor (McBrien et al., 1993a,b). Hypotheses linking protection to variations in dioptric (Flitcroft, 2012) space lack direct experimental support, and while the spatial (Tse et al., 2007; Tse and To, 2011) and temporal (Zhu et al., 2003; Zhu and Wallman, 2009) interplay of myopic and hyperopic defocus has been demonstrated experimentally, how this might work in human indoor and outdoor environments is unclear, given that fixation distance varies considerably outdoors as humans interact with nearby people and objects, rather than gazing fixedly into the distance.

In relation to physical activity, the epidemiological evidence suggests that total time outdoors rather than time spent on physical activity is important, and this was confirmed in animal experiments in which there was no increase in measured activity associated with protection by high light levels (Ashby et al., 2009). Similarly, the limited dynamic range of light-induced pupil constriction does not fit well with the epidemiological evidence, and animal studies using artificial pupils did not support this hypothesis (Ashby et al., 2009).

Animal studies have also given no support to the UV hypothesis, since protection was obtained with UV-free lights (Ashby et al., 2009), and bright UV lights do not provide protection (Hammond and Wildsoet, 2012). In addition, Vitamin D supplementation did not prevent experimental myopia in tree shrews (Vitamin D3 supplement did not affect the development of myopia produced with form deprivation or a minus lens in tree shrews, Siegwart et al. ARVO E-Abstract \# 6298, 2011). Attempts to explore this hypothesis epidemiologically and experimentally have equally not given it strong support (Mutti and Marks, 2011), although associations between Vitamin D receptor polymorphisms and myopia have been reported in humans (Mutti et al., 2011). In relation to spectral composition, recent studies have suggested that rearing animals under red light enhances the development of myopia, while blue light retards it, due to differences in the focal point of these wavelengths within the eye (Long et al., 2009; Rucker and Wallman, 2009), but in general these effects are small relative to epidemiological shifts, and are generally only obtained in much more restricted light environments than are associated with the natural difference between indoors and outdoors.

\section{Quantifying time outdoors}

One of the major challenges in this area is accurately quantifying the amount of time that children spend outdoors. Initial studies have all been performed using questionnaires. These have ranged in complexity from simple questions on the amount of time spent on sports and outdoors, where the underlying logic seemed to be a possible link to physical activity, through to the multi-item questionnaire developed for the Sydney Myopia Study, which was designed to elucidate information on the role of time outdoors and indoors, sport outdoors and indoors, as well as to quantify aspects of near work. As noted above, use of this questionnaire showed that total time outdoors, rather than engagement in sport, was the important factor.

As a result, a new questionnaire was developed by a WHO working party to focus on quantification of time outdoors and aspects of near work. This questionnaire has undergone several minor revisions, and the final form is available at www.gzzoc.com. It has been complemented by a questionnaire on homework and engagement in coaching classes, which is also available online.

At present, none of the questionnaires have been well validated. However, their continuing use can be justified, because these instruments have provided consistent evidence for the importance of 
time outdoors in the aetiology of myopia, which indicates that the effects are quite robust. The original Sydney Myopia Study questionnaire has been administered to two 12-13 year-old cohorts five years apart, with similar results being obtained (French et al., 2013b). The modified WHO questionnaire has also been administered at several sites internationally, giving very different results at sites where the prevalence of myopia is high as compared to those where the prevalence is low (unpublished results). This suggests that the results obtained with these questionnaires are reproducible and sufficiently robust to detect the effects of time outdoors on the development of myopia.

However, for more precise identification of such exposures, particularly in intervention trials, the questionnaires need to validated against more objective measures. This work is currently in progress, using comparison of questionnaire responses to results from a daily activity diary. Validation using experience sampling approaches is also in progress. However, validation against more objective measures such as measurements obtained using wearable detectors such as HOBO light meters or ACTI-watches would be desirable. The HOBO light meters can collect continuous data, and depending on the frequency of recording for many days, and the first steps in their validation have been published (Dharani et al., 2012). Systems based on GPS or mobile phone reception also have potential (Tandon et al., 2013; Zhou et al., 2012 (www.ntu.edu. sg/home/limo/papers/SenSys12_IODetector.pdf).

Another form of objective measurement comes from the use of UV densitometers which have been extensively used in Vitamin D and sun protection research (Parisi and Kimlin, 2004; Parisi et al., 2012), since, even though it appears that UV exposures are not important for the protective effects, UV exposures can give an objective measure of bright light (sun) exposures outdoors. Currently available UV detectors can collect cumulative exposures over several days.

An interesting variation on measuring time outdoors comes from the measurement of UV-induced skin damage, by measuring UV-autofluorescence (Sherwin et al., 2012a,b). This technique has established that in adults, there is a strong correlation between increased UV-damage and lower myopia. However, the relationship between sun exposures and UV-autofluorescence is currently unclear, and the extent to which damage is cumulative or partially reversible is still to be established.

\section{Clinical trials of prevention}

To our knowledge, there are currently three trials on prevention of myopia with time outdoors. Results of a small school-based trial in Cheng-du, China have been published in Chinese (Yi and Li, 2011). This trial reported significant reduction in the progression of myopia in a school-based intervention, from $-0.52 \mathrm{D} /$ year in the control group to $-0.38 \mathrm{D} /$ year in the intervention group. The intervention involved increasing time outdoors and restricting near work, but details of the intervention and the results are very limited.

Results have also been reported from a school-based pilot intervention in a suburban area of southern Taiwan (Wu et al., 2013). The intervention involved turning off classroom lights and emptying classrooms. Children were then encouraged to go outdoors. The total time available for the intervention was $80 \mathrm{~min}$ per day. In non-myopic subjects, the myopic shift in refraction was reduced from $-0.44 \mathrm{D}$ to $-0.28 \mathrm{D}$, but no significant difference was observed in the myopic group. Analysis of progression in those with myopia was complicated by significant use of atropine eye drops to control myopic progression. Importantly, the percentage of new cases of myopia was reduced from $17.65 \%$ in the control school to $8.41 \%$ in the intervention arm.
To our knowledge, the biggest trial is that set up in 2009 in Guangzhou, based at the Zhongshan Ophthalmic Center. The trial was carried out with the full support of the Guangzhou Ministry of Education and the Guangzhou Student Health Bureau, in 12 schools chosen to be representative of the Guangzhou system. Within this group, schools were randomised to the treatment or intervention arms, and all students in Grade 1 participated in the interventions as required by Ministry of Education policy, but optical measurements were gathered only on those who gave informed consent and were formally enrolled in the trial. In the treatment arm of this study, children were given an additional class at school at the end of the school day, during which they spent time outdoors, while in the control arm, the children went home at the normal time. At schools in the intervention arm, education programs for parents were carried out, encouraging them to ensure that their children spend more time outdoors after school, on weekends and during school holidays. Compliance is clearly an issue in trials of this kind, and random study visits from the study team and the Ministry of Education ensured that schools were implementing the program appropriately. In addition, standard questionnaires were administered to all children annually, and in the final data collection period (September-November 2012) sub-samples were examined with HOBO light meters and UV densitometers. Final results from this trial are not yet available, but two annual reports (Xiang et al. IOVS 2011; 52: E-Abstract 3057; Morgan et al. IOVS 2012; 53: E-Abstract 2753 ) suggest that small, but statistically significant, reductions in the development of myopia as measured by a reduction in the decline of mean spherical equivalent refraction and the prevalence of myopia have been achieved. Corresponding reductions in axial elongation were also reported.

These initial results seem to give some proof of principle for the use of interventions based on increasing time outdoors to prevent myopia. One of the important advantages of the approach to prevention through increasing time outdoors is that the approach can be readily applied to all children, not just those with existing myopia, and thus provides an opportunity to prevent the onset of myopia, rather than just limit progression. Another important advantage is that because the interventions are natural and involve variations that are seen in human environments, even if they are not common in some locations, it should be possible to scale up the intervention if small positive changes are achieved initially. This is more difficult with interventions involving spectacles or drugs.

\section{Conclusions}

Research so far has established that children who spend more time outdoors are less likely to be, or become myopic. The effect of time outdoors is robust, and seems to reduce or even negate the influence of factors that may be associated with higher prevalence rates of myopia, such as large amounts of near work, or having myopic parents. The ability of time outdoors to prevent incident myopia suggests that it may be possible to reduce the number of children with school or acquired myopia.

At this stage, it is not clear whether time outdoors also regulates progression in those with established myopia. One major study has reported negative results, but may have statistical limitations associated with the lesser variation in time outdoors in children who have already become myopic. Other reports have shown that there are seasonal variations in progression which are explicable, at least in part, by time outdoors. Since prevalent and incident myopia, as well as myopic progression, depend on axial elongation, further work is needed on whether regulation of axial elongation is similar before and after the onset of clinical myopia.

Some progress has been made in defining the mechanism of the protective effects. From a range of possibilities, the hypothesis that 
protection is based on bright light-stimulated release of dopamine in the retina, has been given support from animal studies. However, the results of animal studies are not entirely consistent, and in particular, while bright light prevents the development of FDM in all species studied so far, results on prevention of LIM, which would seem to be a better model of human myopia, are more variable. Clearly more work in needed in this area as well.

Initial results from three clinical trials of increasing the amount of time that children spend outdoors have given promising results, but final results on the largest study are still pending. If these provide proof of principle for myopia prevention interventions based on bright light exposures, then the next challenge will be to define and implement feasible and effective interventions on a mass scale in locations and communities that are currently characterised by high prevalence rates of myopia, as well as in other locations. If successful, this will provide an excellent example of how integrating human epidemiology and animal studies can be translated into public health approaches which can provide real health benefits.

\section{Q4 Financial support}

The Sydney Myopia Study (SMS) was supported by grant 253732 and the Sydney Adolescent Vascular and Eye Study (SAVES) by grant 512530 from the Australian National Health \& Medical Research Council, and the Westmead Millennium Institute, University of Sydney. The funding organisation had no role in the design or conduct of this research. No conflicting relationship exists for any author.

\section{References}

Ashby, R.S., Schaeffel, F., 2010. The effect of bright light on lens compensation in chicks. Invest. Ophthalmol. Vis. Sci. 51, 5247-5253.

Ashby, R.S., Ohlendorf, A., Schaeffel, F., 2009. The effect of ambient illuminance on the development of deprivation myopia in chicks. Invest. Ophthalmol. Vis. Sci. 50, 5348-5354.

Au Eong, K.G., Tay, T.H., Lim, M.K., 1993a. Education and myopia in 110,236 young Singaporean males. Singapore Med. J. 34, 489-492.

Au Eong, K.G., Tay, T.H., Lim, M.K., 1993b. Race, culture and myopia in 110,236 young Singaporean males. Singapore Med. J. 34, 29-32.

Chew, S.J., Chia, S.C., Lee, L.K., 1988. The pattern of myopia in young Singaporean men. Singapore Med. J. 29, 201-211.

Chou, S.C., Yang, C.H., Lee, C.H., Yang, C.M., Ho, T.C., Huang, J.S., Lin, C.P., Chen, M.S., Shih, Y.F., 2007. Characteristics of primary rhegmatogenous retinal detachment in Taiwan. Eye (Lond) 21 (8), 1056-1061.

Cohen, Y., Belkin, M., Yehezkel, O., Solomon, A.S., Polat, U., 2011. Dependency between et intensity and refractive development under light-dark cycles. Exp. Eye Res. 92, 40-46.

Cohen, Y., Peleg, E., Blekin, M., Polat, U., Solomon, A.S., 2012. Ambient illuminance, retinal dopamine release and refractive development in chicks. Exp. Eye Res. $103,33-40$.

Cui, D., Trier, K., Munk Ribel-Madsen, S., 2013. Effect of day length on eye growth, myopia progression, and change of corneal power in myopic children. Ophthalmology. (Epub Feb 2013).

Dharani, R., Lee, C.F., Theng, Z.X., Drury, V.B., Ngo, C., Sandar, M., Wong, T.Y., Finkelstein, E.A., Saw, S.M., 2012. Comparison of measurements of time outdoors and light levels as risk factors for myopia in young Singapore children. Eye (Lond) 26, 911-918.

Dirani, M., Tong, L., Gazzard, G., Zhang, X., Chia, A., Young, T.L., Rose, K.A., Mitchell, P., Saw, S.M., 2009. Outdoor activity and myopia in Singapore teenage children. Br. J. Ophthalmol. 93, 997-1000.

Donovan, L., Sankaridurg, P., Ho, A., Chen, X., Lin, Z., Thomas, V., Smith, E.L., Ge, J., Holden, B., 2012. Myopia progression in Chinese children is slower in summer than in winter. Optom. Vis. Sci. 89, 1196-1202.

Feldkaemper, M., Schaeffel, F., 2013. An updated view on the role of dopamine in myopia. Exp. Eye Res.. (Epub Feb 19 in this issue).

Flitcroft, D.I., 2012. The complex interactions of retinal, optical and environmental factors in myopia aetiology. Prog. Retin. Eye Res. 31, 622-660.

French, A.N., Morgan, I.G., Mitchell, P., Rose, K.A., 2013a. Risk factors for incident myopia in Australian school children: the Sydney adolescent vascular and eye study. Ophthalmology (in press).

French, A.N., Morgan, I.G., Mitchell, P., Rose, K.A., 2013b. Children's pattern of activities and the development of myopia. Ophthalmic Physiol. Opt. (in press).
Fujiwara, M., Hasebe, S., Nakanishi, R., Tanigawa, K., Ohtsuki, H., 2012. Seasonal variation in myopia progression and axial elongation: an evaluation of Japanese children participating in a myopia control trial. Jpn. J. Ophthalmol. 56, 401-406.

Fulk, G.W., Cyert, L.A., Parker, D.A., 2002. Seasonal variation in myopia progression and ocular elongation. Optom. Vis. Sci. 79, 46-51.

Goh, W.S., Lam, C.S., 1994. Changes in refractive trends and optical components of Hong Kong Chinese aged 19-39 years. Ophthalmic Physiol. Opt. 14, 378-382.

Goss, D.A., Rainey, B.B., 1998. Relation of childhood myopia progression rates to time of year. J. Am. Optom. Assoc. 69, 262-266.

Guggenheim, J.A., Northstone, K., McMahon, G., Ness, A.R., Deere, K., Mattocks, C., Pourcain, B.S., Williams, C., 2012. Time outdoors and physical activity as predictors of incident myopia in childhood: a prospective cohort study. Invest. Ophthalmol. Vis. Sci. 53, 2856-2865.

Guo, Y., Liu, L.J., Xu, L., Lv, Y.Y., Tang, P., Feng, Y., Meng, M., Jonas, J.B., 2013. Outdoor activity and myopia among primary students in rural and urban regions of Beijing. Ophthalmology 120, 277-283.

Hammond, D.S., Wildsoet, C.F., 2012. Compensation to positive as well as negative lenses can occur in chicks reared in bright UV lighting. Vis. Res. 67, 44-50.

He, M., Zeng, J., Liu, Y., Xu, J., Pokharel, G.P., Ellwein, L.B., 2004. Refractive error and visual impairment in urban children in southern China. Invest. Ophthalmol. Vis. Sci. 45, 793-799.

Ip, J.M., Saw, S.M., Rose, K.A., Morgan, I.G., Kifley, A., Wang, J.J., Mitchell, P., 2008 Role of near work in myopia: findings in a sample of Australian school children. Invest. Ophthalmol. Vis. Sci. 49, 2903-2910.

Iuvone, P.M., Tigges, M., Stone, R.A., Lambert, S., Laties, A.M., 1991. Effects of apomorphine, a dopamine receptor agonist, on ocular refraction and axial elongation in a primate model of myopia. Invest. Ophthalmol. Vis. Sci. 32, 1674-1677.

Jacobsen, N., Jensen, H., Goldschmidt, E., 2008. Does the level of physical activity in university students influence development and progression of myopia? - a 2year prospective cohort study. Invest. Ophthalmol. Vis. Sci. 49, 1322-1327.

Jobke, S., Kasten, E., Vorwerk, C., 2008. The prevalence rates of refractive errors among children, adolescents, and adults in Germany. Clin. Ophthalmol. 2, 601-607.

Jones, L.A., Sinnott, L.T., Mutti, D.O., Mitchell, G.L., Moeschberger, M.L., Zadnik, K., 2007. Parental history of myopia, sports and outdoor activities, and future myopia. Invest. Ophthalmol. Vis. Sci. 48, 3524-3532.

Jones-Jordan, L.A., Mitchell, G.L., Cotter, S.A., Kleinstein, R.N., Manny, R.E., Mutti, D.O., Twelker, J.D., Sims, J.R., Zadnik, K., 2011. Visual activity before and after the onset of juvenile myopia. Invest. Ophthalmol. Vis. Sci. 52, 1841-1850.

Jones-Jordan, L.A., Sinnott, L.T., Cotter, S.A., Kleinstein, R.N., Manny, R.E., Mutti, D.O. Twelker, J.D., Zadnik, K., 2012. Time outdoors, visual activity, and myopia progression in juvenile-onset myopes. Invest. Ophthalmol. Vis. Sci. 53, 7169-7175.

Jung, S.K., Lee, J.H., Kakizaki, H., Jee, D., 2012. Prevalence of myopia and its association with body stature and educational level in 19-year-old male conscripts in Seoul, South Korea. Invest. Ophthalmol. Vis. Sci. 53, 5579-5583.

Kempen, J.H., Mitchell, P., Lee, K.E., Tielsch, J.M., Broman, A.T., Taylor, H.R., Ikram, M.K., Congdon, N.G., O'Colmain, B.J., 2004. The prevalence of refractive errors among adults in the United States, Western Europe, and Australia. Arch. Ophthalmol. 122, 495-505.

Khader, Y.S., Batayha, W.Q., Abdul-Aziz, S.M., Al-Sheik-Kalil, M.I., 2006. Prevalence and risk indicators of myopia among schoolchildren in Amman, Jordan. East. Mediterr. Health J. 12, 434-439.

Leske, M.C., Chylack, L.T., Wu, S.Y., 1991. The lens opacities case-control study. Risk factors for cataract. Arch. Ophthalmol. 109, 244-251.

Lin, L.L., Shih, Y.F., Hsiao, C.K., Chen, C.J., 2004. Prevalence of myopia in Taiwanese schoolchildren: 1983 to 2000. Ann. Acad. Med. Singapore 33, 27-33.

Logan, N.S., Davies, I.N., Mallen, E.A., Gilmartin, B., 2005. Ametropia and ocular biometry in a U.K. university student population. Optom. Vis. Sci. 82, 261-266.

Long, Q., Chen, D., Chu, R., 2009. Illumination with monochromatic longwavelength light promotes myopic shift and ocular elongation in newborn pigmented guinea pigs. Cutan. Ocul. Toxicol. 28, 176-180.

Low, W., Dirani, M., Gazzard, G., Chan, Y.H., Zhou, H.J., Selvaraj, P., Au Eong, K.G., Young, T.L., Mitchell, P., Wong, T.Y., Saw, S.M., 2010. Family history, near work outdoor activity, and myopia in Singapore Chinese preschool children. Br. J. Ophthalmol. 94, 1012-1016.

Lu, B., Congdon, N., Liu, X., Choi, K., Lam, D.S., Zhang, M., Zheng, M., Zhou, Z., Li, L., Liu, X., Sharma, A., Song, Y., 2009. Associations between near work outdoor activity, and myopia among adolescent students in rural China: the Xichang pediatric refractive error study report no. 2. Arch. Ophthalmol. 127, 769-775.

Marcus, M.W., de Vries, M.M., Junoy Montolio, F.G., Jansonius, N.M., 2011. Myopia as a risk factor for open-angle glaucoma: a systematic review and meta-analysis. Ophthalmology 118, 1989-1994.

Matsumura, H., Hirai, H., 1999. Prevalence of myopia and refractive changes in students from 3 to 17 years of age. Surv. Ophthalmol. 44 (Suppl. 1), S109-S115.

McBrien, N.A., Moghaddam, H.O., New, R., Williams, L.R., 1993a. Experimental myopia in a diurnal mammal (Sciurus carolinensis) with no accommodative ability. J. Physiol. 469, 427-441.

McBrien, N.A., Moghaddam, H.O., Reeder, A.P., 1993b. Atropine reduces experimental myopia and eye enlargement via a nonaccommodative mechanism. Invest. Ophthalmol. Vis. Sci. 34, 205-215.

McCarthy, C.S., Megaw, P., Devadas, M., Morgan, I.G., 2007. Dopaminergic agents affect the ability of brief periods of normal vision to prevent form-deprivation myopia. Exp. Eye Res. 84, 100-107. 
Megaw, P.L., Morgan, I.G., Boelen, M.K., 1997. Dopaminergic behaviour in chicken retina and the effect of form deprivation. ANZ J. Ophthalmol. 25 (Suppl. 1), S76-S78.

Megaw, P., Morgan, I., Boelen, M., 2001. Vitreal dihydroxyphenylacetic acid (DOPAC) as an index of retinal dopamine release. J. Neurochem. 76, 1636-1644.

Megaw, P.L., Boelen, M.G., Morgan, I.G., Boelen, M.K., 2006. Diurnal patterns of dopamine release in chicken retina. Neurochem. Int. 48, 17-23.

Morgan, I.G., Boelen, M.K., 1996. Complexity of dopaminergic function in the retinal dark-light switch. Aust. N. Z. J. Ophthalmol. 24 (Suppl. 1), 56-58.

Morgan, I., Rose, K., 2005. How genetic is school myopia? Prog. Retin. Eye Res. 24 $1-38$.

Morgan, I.G., Rose, K.A., 2013. Myopia and international educational performance. Ophthalmic Physiolog Opt. (in press).

Morgan, I.G., Ohno-Matsui, K., Saw, S.M., 2012. Myopia. Lancet 379, 1739-1748.

Mutti, D.O., Marks, A.R., 2011. Blood levels of vitamin D in teens and young adults with myopia. Optom. Vis. Sci. 88, 377-382.

Mutti, D.O., Zadnik, K., 2009. Has near work's star fallen? Optom. Vis. Sci. 86, 76-78.

Mutti, D.O., Mitchell, G.L., Moeschberger, M.L., Jones, L.A., Zadnik, K., 2002. Parental myopia, near work, school achievement, and children's refractive error. Invest. Ophthalmol. Vis. Sci. 43, 3633-3640.

Mutti, D.O., Cooper, M.E., Dragan, E., Jones-Jordan, L.A., Bailey, M.D., Marazita, M.L Murray, J.C., Zadnik, K., 2011. Vitamin D receptor (VDR) and group-specific component (GC, vitamin D-binding protein) polymorphisms in myopia. Invest. Ophthalmol. Vis. Sci. 52, 3818-3824.

Napper, G.A., Brennan, N.A., Barrington, M., Squires, M.A., Vessey, G.A., Vingrys, A.J., 1995. The duration of normal visual exposure necessary to prevent form deprivation myopia in chicks. Vis. Res. 35, 1337-1344.

Napper, G.A., Brennan, N.A., Barrington, M., Squires, M.A., Vessey, G.A., Vingrys, A.J., 1997. The effect of an interrupted daily period of normal visual stimulation on form deprivation myopia in chicks. Vis. Res. 37, 1557-1564.

Onal, S., Toker, E., Akingol, Z., Arslan, G., Ertan, S., Turan, C., Kaplan, O., 2007. Refractive errors of medical students in Turkey: one year follow-up of refraction and biometry. Optom. Vis. Sci. 84, 175-180.

Parisi, A.V., Kimlin, M.G., 2004. Personal solar UV exposure measurements employing modified polysulphone with an extended dynamic range. Photochem. Photobiol. 79, 411-415.

Parisi, A.V., Eley, R., Downs, N., 2012. Determination of the usage of shade structures via a dosimetry technique. Photochem. Photobiol. 88, 1012-1015.

Parssinen, O., Lyyra, A.L., 1993. Myopia and myopic progression among schoolchildren: a three-year follow-up study. Invest. Ophthalmol. Vis. Sci. 34, 2794-2802.

Qian, Y.S., Chu, R.Y., He, J.C., Sun, X.H., Zhou, X.T., Zhao, N.Q., Hu, D.N., Hoffman, M.R. Dai, J.H., Qu, X.M., Pao, K.E., 2009. Incidence of myopia in high school students with and without red-green color vision deficiency. Invest. Ophthalmol. Vis. Sci. $50,1598-1605$

Quek, T.P. Chua, C.G, Chong C.S, Chong J.H. Hey, H.W. Lee, J. Lim, Y.F, Saw, S.M 2004. Prevalence of refractive errors in teenage high school students in Singapore. Ophthalmic Physiol. Opt. 24, 47-55.

Resnikoff, S., Pascolini, D., Mariotti, S.P., Pokharel, G.P., 2008. Global magnitude of visual impairment caused by uncorrected refractive errors in 2004. Bull. World Health Organ. 86, 63-70.

Rose, K.A., Morgan, I.G., Ip, J., Kifley, A., Huynh, S., Smith, W., Mitchell, P., 2008a. Outdoor activity reduces the prevalence of myopia in children. Ophthalmology $115,1279-1285$

Rose, K.A., Morgan, I.G., Smith, W., Burlutsky, G., Mitchell, P., Saw, S.M., 2008b. Myopia, lifestyle, and schooling in students of Chinese ethnicity in Singapore and Sydney. Arch. Ophthalmol. 126, 527-530.

Rucker, F.J., Wallman, J., 2009. Chick eyes compensate for chromatic simulations of hyperopic and myopic defocus: evidence that the eye uses longitudinal chromatic aberration to guide eye-growth. Vis. Res. 49, 1775-1783.

Saw, S.M., Hong, R.Z., Zhang, M.Z., Fu, Z.F., Ye, M., Tan, D., Chew, S.J., 2001a. Nearwork activity and myopia in rural and urban schoolchildren in China. J. Pediatr. Ophthalmol. Strabismus 38, 149-155.

Saw, S.M. Wu, H.M., Seet, B., Wong T.Y., Yap, E. Chia, K.S., Stone, R.A., Lee, L., 2001b. Academic achievement, close up work parameters, and myopia in Singapore military conscripts. Br. J. Ophthalmol. 85, 855-860.

Saw, S.M., Zhang, M.Z., Hong, R.Z., Fu, Z.F., Pang, M.H., Tan, D.T., 2002. Near-work activity, night-lights, and myopia in the Singapore-China study. Arch. Ophthalmol. 120, 620-627.
Saw, S.M., Tong, L., Chua, W.H., Chai, K.S., Koh, D., Tan, D.T., Katz, J., 2005. Incidence and progression of myopia in Singaporean school children. Invest. Ophthalmol. Vis. Sci. 46, $51-57$.

Saw, S.M., Shankar, A., Tan, S.B., Taylor, H., Tan, D.T., Stone, R.A., Wong, T.Y., 2006. A cohort study of incident myopia in Singaporean children. Invest. Ophthalmol. Vis. Sci. 47, 1839-1844.

Saw, S.M., Cheng, A., Fong, A., Gazzard, G., Tan, D.T., Morgan, I., 2007. School grades and myopia. Ophthalmic Physiol. Opt. 27, 126-129.

Sherwin, J.C., Hewitt, A.W., Coroneo, M.T., Kearns, L.S., Griffiths, L.R., Mackey, D.A., 2012a. The association between time spent outdoors and myopia using a novel biomarker of outdoor light exposure. Invest. Ophthalmol. Vis. Sci. 53, 43634370.

Sherwin, J.C., Reacher, M.H., Keogh, R.H., Khawaja, A.P., Mackey, D.A., Foster, P.J., 2012b. The association between time spent outdoors and myopia in children and adolescents: a systematic review and meta-analysis. Ophthalmology 119, 2141-2151.

Shih, Y.F., Chiang, T.H., Lin, L.L., 2009. Lens thickness changes among schoolchildren in Taiwan. Invest. Ophthalmol. Vis. Sci. 50, 2637-2644.

Smith, E.L., Hung, L.F., Huang, J., 2012. Protective effects of high ambient lighting on the development of form-deprivation myopia in rhesus monkeys. Invest. Ophthalmol. Vis. Sci. 53, 421-428.

Smith, E.L., Hung, L.F., Arumugan, B., Huang, J., 2013. Negative-lens-induced myopia in infant monkeys. Invest. Ophthalmol. Vis. Sci.. (E-Pub April 4).

Stone, R.A., Lin, T., Laties, A.M. Iuvone, P.M., 1989. Retinal dopamine and formdeprivation myopia. Proc. Natl. Acad. Sci. U. S. A. 86, 704-706.

Tan, N.W., Saw, S.M., Lam, D.S., Cheng, H.M., Rajan, U., Chew, S.J., 2000. Temporal variations in myopia progression in Singaporean children within an academic year. Optom. Vis. Sci. 77, 465-472.

Tandon, P.S., Saelens, B.E., Zhou, C., Kerr, J., Christakis, D.A., 2013. Indoor versus outdoor time in preschoolers at child care. Am. J. Prevent. Med. 44, 85-88.

Tay, M.T., Au Eong, K.G., Ng, C.Y., Lim, M.K., 1992. Myopia and educational attainment in 421,116 young Singaporean males. Ann. Acad. Med. Singapore $21,785-791$.

Tse, D.Y., To, C.H., 2011. Graded competing regional myopic and hyperopic defocus produces summated emmetropization set points in chick. Invest. Ophthalmol. Vis. Sci. 52, 8056-8062.

Tse, D.Y., Lam, C..S., Guggenheim, J.A., Lam, C., Li, K.K., Liu, Q., To, C.H., 2007. Simultaneous defocus integration during refractive development. Invest. Ophthalmol. Vis. Sci. 48, 5352-5359.

Vitale, S., Ellwein, L.B., Cotch, M.F., Ferris, F.L., Sperduto, R.D., 2008. Prevalence of refractive error in the United States, 1999-2004. Arch. Ophthalmol. 126, $1111-1119$.

Vitale, S., Sperduto, R.D., Ferris, F.L., 2009. Increased prevalence of myopia in the United States between 1971-1972 and 1999-2004. Arch. Ophthalmol. 127, $1632-1639$.

Vongphanit, J., Mitchell, P., Wang, J.J., 2002. Prevalence and progression of myopic retinopathy in an older population. Ophthalmology 109, 704-711.

Wojciechowski, R., 2011. Nature and nurture: the complex genetics of myopia and refractive error. Clin. Genet. 79, 301-320.

Wu, H.M., Seet, B., Yap, E.P., Saw, S.M., Lim, T.H., Chia, K.S., 2001. Does education explain ethnic differences in myopia prevalence? A population-based study of young adult males in Singapore. Optom. Vis. Sci. 78, 234-239.

Wu, P.C., Tsai, C.L., Hu, C.H., Yang, Y.H., 2010. Effects of outdoor activities on myopia among rural school children in Taiwan. Ophthalmic Epidemiol. 17, 338-342.

Wu, P.C. Tsai, C.L. Wu, H.L. Yang, Y.H., Kuo, H.K., 2013. Outdoor activity during class recess reduces myopia onset and progression in school children. Ophthalmology (in press).

Yi, J.H., Li, R.R., 2011. Influence of near-work and outdoor activities on myopia progression in school children (in Chinese). Zhongguo Dang Dai Er Ke Za Zhi 13, $32-35$.

Zhan, M.Z., Saw, S.M., Hong, R.Z., Fu, Z.F., Yang, H., Shui, Y.B., Yap, M.K., Chew, S.J., 2000. Refractive errors in Singapore and Xiamen, China-a comparative study in school children aged 6 to 7 years. Optom. Vis. Sci. 77, 302-308.

Zhu, X., Wallman, J., 2009. Temporal properties of compensation for positive and negative spectacle lenses in chicks. Invest. Ophthalmol. Vis. Sci. 50, 37-46.

Zhu, X., Winawer, J.A., Wallman, J., 2003. Potency of myopic defocus in spectacle lens compensation. Invest. Ophthalmol. Vis. Sci. 44, 2818-2827. 